\title{
Introductory notes for the Acta IMEKO special section on the IMEKO TC17 co-sponsored international conference ISMCR'2019
}

\author{
Yvan Baudoin ${ }^{1}$, Yves Dubucq ${ }^{2}$, Frank E. Schneider ${ }^{3}$, Tim Van Langenhoven ${ }^{4}$ \\ ${ }_{1}^{1}$ Professor emeritus Royal Military Academy, Manager ICI/ERKC, www.ici-belgium.be \\ 2 Director of the International CBRNE Institute, Belgium \\ ${ }^{3}$ Deputy Head of the Cognitive Mobile Systems Department (CMS), Fraunhofer Institute for Communication, Information Processing and \\ Ergonomics FKIE \\ ${ }^{4}$ Director of the Royal Higher Institute for Defence, Belgium
}

\begin{abstract}
Section: Editorial
Citation: Yvan Baudoin, Yves Dubucq, Frank E. Schneider, Tim Van Langenhoven, Introductory notes for the Acta IMEKO Special Section on the IMEKO TC17 cosponsored international conference ISMCR'2019, Acta IMEKO, vol. 8, no. 4, article 1, December 2019, identifier: IMEKO-ACTA-08 (2019)-04-01
\end{abstract}

Editor: Dušan Agrež, University of Ljubljana, Slovenia

Received November 26, 2019; In final form November 26, 2019; Published December 2019

Copyright: This is an open-access article distributed under the terms of the Creative Commons Attribution 3.0 License, which permits unrestricted use, distribution, and reproduction in any medium, provided the original author and source are credited.

Corresponding author: Yvan Baudoin, e-mail: yvan.baudoin@ici-belgium.be

\section{Distinguished Readers,}

From 24 to 27 September 2018, on the 'HAINAUT Security' site, located in BAUFFE (Mons, close to CHIEVRE airport and CASTEAU NATO headquarters), the annual competitions were held to demonstrate the capabilities of mobile robots in realistic scenarios. In 2011, this competition, devoted exclusively on Research and Development, brought together six European teams focusing on applications related to civilian security missions, on the site of the Belgian Defence Demining Service, in a wooded area. In 2016, the Austrian Ministry of Defence, supported by the NATO EOD Centre of Excellence, managed the ELROB tests entrusted to twelve European teams, focusing on the essential military applications: recognition of potential dangers in urban sites, transport conveying of equipment, search and rescue of victims, detection of explosive devices and mine neutralization.

2018 sees the execution of these same scenarios to which has been added the detection of improvised explosive devices (terrorist threat) and the evacuation of victims, scenarios favoured by Defence experts gathered in research groups of the Organization 'Science and Technology' of NATO.

The ELROB'2018 competition presented 16 teams of which five (NIC Instruments Ltd-UK, TELEROB GmbH-GE, BROKK Ltd.-SE, ELP GmbH-GE, TAUT-AT) have been tested on explosive device detection capabilities and seven competitors tested on rescue capabilities for victims (TELEROB
GmbH-GE, Fraunhofer \& TNO-GE-NL, BISG-FI, TAUT, BROKK and ELP, AVRORA-RU).

The aim of these competitions is to promote the best advances in technology and to strengthen cooperation in research.

Priority is today given to monitoring and reconnaissance missions and to the specific examination of suspect areas or areas affected by CBRN-type contaminations: the recent example of measures to confirm the use or location of chemical weapons in Syria, as well as the use of drones for the detection of mineinfested areas in Croatia confirm the interest of these machines.

It is now utopian to legislate on the prohibition of 'combat' or 'combat support' drones, as investments in this area are very much involved while the role of drones alongside fighter planes is already essential: the conflicts affected by the intensive use of bombing (and precise targeting by some drones) are unfortunately, since the Second World War, pests in terms of civilian casualties: the Balkans yesterday, Afghanistan, Syria, Yemen, between others, emphasize this damage.

The United States are obviously very involved in the development of drones of different categories (ROVER system, PREDATOR, MQ-5B HUNTER ...) but the European countries like France, Germany, Italy and Great Britain also have invested and also invest in drones in the arms industry, supported by NATO, the European Defence Agency or even the European Commission (oriented towards the civil security of the European area). These investments are in billions and today pose many problems in terms of intrinsic safety of the vehicles used (their 
autonomy, control-or loss of control-possible interference with air traffic, reliability of communications, etc.) and in the field of ethics (protection of privacy, for example) but also interdependence between man and machine.

The ELROB event has been doubled in 2018 by the organization of the $21^{\text {st }}$ International Symposium on Robotics (ISMCR'2018) under the auspices of the International Measurement Confederation IMEKO, and more particularly its technical committee (TC17) coordinator of research in robotics, chaired by Japan, of which Belgium is an active member in charge of the organization of this symposium.

The International CBRNE Institute (located in Belgium www.ici-belgium.be), aware on the above threats, decided to host and co-organize the competition ELROB and the ISMCR'2018. Focus on Mobile Robotics has attracted, beside the 16 speakers of the ELROB competition also 27 contributors from 10 countries.

The contributions were presented during two days, introduced by six Key-note speakers, namely Lieutenant Colonel MONET (France), Dr Kris KIDD (TOTAL), Prof E. M. GRADETSKY (Russia), Prof INAMI (secretary TC17, Japan), Dr. Ir. J. PINK (UK co-organizer of ELROB'2018).

The topics of the ISMCR'2019 may be summarized as follows:

- $\quad$ E-training and Simulations of Robotics Systems (4 papers)

- $\quad$ Measurement and Control with sensor Systems (3 papers)

- $\quad$ Intelligent mapping and Navigation (5 papers)

- $\quad$ Architecture of Robotics Systems (7 papers)

- Artificial Intelligence (2 papers)

- Validation through state-of-the-art of mobile robotics systems (4 papers)

We are delighted to provide the readers around the world the opportunity to access the recent advancements in robotics, mobile robotics in particular, especially in dynamic conditions. We are looking for new innovations to arise from this scientifically sound base.

The here presented release is the result of hard but rewarding scientific work, with authors, reviewers, copy-editors, layout editors and, last but not least, the Editor in Chief, Prof. Dušan Agrež, providing his support for all this period.

Yvan Baudoin

Guest Editor 